\title{
Propagation Model in Indoor and Outdoor for the LTE Communications
}

\author{
Sun-Kuk Noh $\mathbb{D}^{1}$ and DongYou Choi $\mathbb{D}^{2}$ \\ ${ }^{1} S W$ Convergence Institute, Chosun University, Gwangju, Republic of Korea \\ ${ }^{2}$ Dept. of Information and Communications, Chosun University, Gwangju, Republic of Korea
}

Correspondence should be addressed to DongYou Choi; dychoi@chosun.ac.kr

Received 11 February 2019; Revised 29 April 2019; Accepted 14 May 2019; Published 16 June 2019

Academic Editor: Christoph F. Mecklenbräuker

Copyright (C) 2019 Sun-Kuk Noh and DongYou Choi. This is an open access article distributed under the Creative Commons Attribution License, which permits unrestricted use, distribution, and reproduction in any medium, provided the original work is properly cited.

\begin{abstract}
Rapidly rising demand for radio communication and the explosion in the number of mobile communications service subscribers have led to the need for optimization in the development of fifth-generation (5G) mobile communication systems. Previous studies on the development of propagation models considering a propagation environment in the existing microwave band have been mainly focused on analyzing the propagation characteristics with regard to large-scale factors such as path losses, delay propagation, and angle diffusions. In this paper, we investigated the concept of spatial and time changes ratios in the measurement of wave propagations and measured RSRP of Long Term Evolution (LTE) signals at three locations considering the time rate of $1 \%$ and $50 \%$. We confirmed the concept of spatial and time changes rate based on the results of analyzing the signal data measured and proposed the propagation models 1 and 2 in microcell downtown. The forecast results using proposed models 1 and 2 were better than the COST231 model in both indoor and outdoor measured places. It was predicted between a time rate of $1 \%$ and $50 \%$ indoor within $400 \mathrm{~m}$ and outdoor within $200 \mathrm{~m}$. In the future, we will study the propagation model of $5 \mathrm{G}$ mobile communication as well as the current $4 \mathrm{G}$ communication using artificial intelligence technology.
\end{abstract}

\section{Introduction}

Rapidly rising demand for radio communication and the explosion in the number of mobile communications service subscribers have led to the need for optimization in the development of fifth-generation $(5 \mathrm{G})$ mobile communication systems. 5G mobile systems will encompass frequencies from $0.5 \mathrm{GHz}$ to $100 \mathrm{GHz}$ [1]. The development of competitive 5G wireless transmission technology and efficient frequency-use research are based on understanding the characteristics of the exact radio channel. In terms of developments in next generation mobile communication systems, performance verification of the development system is essential, for which it is necessary to estimate the exact wireless-space channel [2]. This is because this channel is based on the exact model, including elements of the wireless transmission applications, such as frequency, time, space, and polarization [3-8].

Previous studies on the development of propagation models considering a propagation environment in the existing microwave band have been mainly focused on analyzing the propagation characteristics with regard to large-scale factors such as path losses, delay propagation, and angle diffusions [9-13]. However, considering the mobility of the surrounding environment, the existing propagation models show large prediction errors when predicting propagations; furthermore, it is difficult to compare the signal strength of homogeneous/heterogeneous systems by using such propagation models. Generally, in order to design a radio station, which can provide radio communication service with a certain level of quality, information on the radio signal power and radio noise power in the applicable areas should be obtained beforehand. In other words, it is required to obtain the information on the radio signals and noise in the applicable areas to design communication systems that ensure that the communication service quality is higher than a certain standard. Therefore, it is required to consider the propagation environment and mobility during propagation prediction. In addition, a time-varying propagation model that considers time and spatial changes is required when 
performing interference analysis using the results of the propagation prediction [14].

In this study, we investigate the concept of spatial and time changes rate in the measurement of wave propagations and measure the reference signal receive power (RSRP) of Long Term Evolution (LTE) signals at three locations in downtown considering the time rate of $1 \%$ and $50 \%$. We confirm the concept of spatial and time changes rates based on the results of analyzing the signal data measured. Based on these results, we propose a propagation model considering distance and frequency in microcell downtown environment.

The rest of the paper is organized as follows: Section 2 describes wave propagation model. Section 3 gives the propagation characteristics by considering the time and spatial changes. Section 4 describes RSRP measurements and results analysis. Section 5 describes proposal of propagation model. Finally, Section 6 is conclusions.

\section{The Wave Propagation Model}

The wave propagation model is based on the measurement results. This is because the measurement environment includes the shadowing parameter in a microcell urban environment that includes multipath fading. In other words, the shadowing parameter is used for considering the signal powers measured at two different locations even along the distance between the same transceiver and the surrounding objects; therefore, the path loss $\mathrm{PL}(\mathrm{d})$ in a specific location has random values with log-normal distribution. The general form of the model is as follows.

$$
\begin{aligned}
\mathrm{PL}(\mathrm{d})[\mathrm{dB}] & =\overline{\mathrm{PL}(\mathrm{d})}+\mathrm{X}_{\sigma} \\
& =\mathrm{PL}\left(\mathrm{d}_{\mathrm{o}}\right)+10 \times \mathrm{n} \times \log \left(\frac{\mathrm{d}}{\mathrm{d}_{\mathrm{o}}}\right)+\mathrm{X}_{\sigma}
\end{aligned}
$$

In the above equation, $\mathrm{n}$ is path loss index, $\mathrm{d}$ is distance between base station (BS) and mobile station (MS), do is reference distance, and $\mathrm{X} \sigma$ is a random variable with an average mean $(\mathrm{m})$ of 0 and log-normal distribution with standard deviation of $\sigma$, wherein the log-normal distribution represents the shadowing effect. In addition, the transmission medium (communication channel) model can be represented in two parts as follows by designating the mobile phone signal as $r(t)$.

$$
\begin{aligned}
\mathrm{r}(\mathrm{t}) & =\mathrm{m}(\mathrm{t}) r_{0}(t) \\
\text { or } r_{0}(t)[\mathrm{dB}] & =\mathrm{r}(\mathrm{t})-\mathrm{m}(\mathrm{t})
\end{aligned}
$$

In (2), $\mathrm{m}(\mathrm{t})$ denotes long term fading, slow fading, and log-normal fading, whose values vary according to the topography between the base station and the mobile terminal. A $r_{0}(t)$ denotes short term fading, fast fading, multipath fading, and Rayleigh fading, which occur owing to the reflections from the surrounding buildings or structures.

\section{The Propagation Characteristics by Considering the Time and Spatial Changes}

The characteristics of the radio propagation signal according to time and space change rate can be defined as follows, similar to the radio fading rate, in ITU-R Recommendations $[15,16]$. The ITU-R P. 1546 is a method for point-to-area predictions for terrestrial services in the frequency range 30 $\mathrm{MHz}$ to $3000 \mathrm{MHz}$.

(1) Changes in the received signals are closely related to the temporal and spatial characteristics.

(2) Measurements of the received signals must be performed for a considerable time at a fixed point.

(3) The expression and analysis of the measured signals are represented in terms of the probability distribution and statistical data obtained during the measurement time.

3.1. Time Changes Rate, Percentage of Time, $\mathrm{p}_{\mathrm{T}} \%$. In all mobile systems, the variations in the electric field strength for wave reception are mainly influenced by fading, and, in particular, significant variations are observed in the shortwave band; therefore, automatic recording is continuously performed at the general interval of 10-30 min because measuring the electric field strength at a certain time is unnecessary. Subsequently, on the basis of these results, the percentage (\%) of time corresponding to a certain value in decibels $(\mathrm{dB})$ or more is determined.

For example, when $50 \%$ value corresponds to $30 \mathrm{~dB}$ for $10 \mathrm{~min}$ from the continuous measurement results, it implies that a value greater than $30 \mathrm{~dB}$ exists in the 5 min period out of the 10 min measurement time. The percentages of time are purposely selected as $5 \%, 10 \%, 50 \%, 90 \%, 95 \%$, etc.; however, $50 \%$ is commonly selected as the percentage of time, and, therefore, it is also known as the median value. In order to provide service coverage at any location, the received electric field strength should be much higher than the minimally required electric field strength.

3.2. Spatial Change Rate, Percentage of Location, $\mathrm{p}_{\mathrm{S}} \%$. The line of sight (LOS) and non-line of sight (NLOS) were considered in downtown areas by considering the applicable frequencies $(\mathrm{MHz})$ and distance $(\mathrm{m})$ in the transmission measurements for reflecting the spatial rates; the process in steps based on ITU-R P. 1411-5 is as follows [15].

$$
\begin{aligned}
& L_{\text {Los }}^{\text {median }}(\mathrm{d})=32.45+20 \log f+20 \log \left(\frac{\mathrm{d}}{1000}\right) \\
& \Delta \mathrm{L}_{\text {LoS }}(\mathrm{p})=1.5624 \sigma\left(\sqrt{-2 \ln \left(1-\frac{p}{100}\right)}-1.1774\right) \\
& \text { with } \sigma=7 d B \\
& L_{\text {LoS }}(\mathrm{d}, \mathrm{p})=L_{\text {LoS }}^{\text {median }}(d)+\Delta L_{\text {LoS }}(p)
\end{aligned}
$$


TABLE 1: LoS and NLoS location variability corrections [15].

\begin{tabular}{lccc}
\hline $\mathrm{p}_{\mathrm{S}}(\%)$ & $\Delta \mathrm{L}_{\mathrm{LoS}}(\mathrm{dB})$ & $\Delta \mathrm{L}_{\mathrm{NLOS}}(\mathrm{dB})$ & $\mathrm{d}_{\mathrm{LoS}}(\mathrm{m})$ \\
\hline 1 & -11.3 & -16.3 & 976 \\
\hline 10 & -7.9 & -9.0 & 276 \\
\hline 50 & 0.0 & 0.0 & 44 \\
\hline 90 & 10.6 & 9.0 & 16 \\
\hline 99 & 20.3 & 16.3 & 10 \\
\hline
\end{tabular}

$$
L_{\text {NLos }}^{\text {median }}(\mathrm{d})=9.5+45 \log f+40 \log \left(\frac{\mathrm{d}}{1000}\right)+L_{\text {urban }}
$$

with $6.8 d B$ (urban), $2.3 d B$ (dense urban)

$$
\begin{aligned}
& \Delta L_{N L o S}(p)=\sigma N^{-1}\left(\frac{p}{100}\right) \text { with ith } \sigma=7 d B \\
& L_{N L o S}(\mathrm{~d}, \mathrm{p})=L_{N L S}^{\text {median }}(d)+\Delta L_{N L o S}(p) \\
& d_{L o S}(\mathrm{p})=212\left[\log \left(\frac{p}{100}\right)^{2}-64 \log \left(\frac{p}{100}\right)\right.
\end{aligned}
$$

$d_{\text {LoS }}(\mathrm{p})=79.2-70\left(\frac{p}{100}\right) \quad$ otherwise

(i) If $\mathrm{d}<d_{L o S}$, then $\mathrm{L}(\mathrm{d}, \mathrm{p})=L_{L o S}(d, p)$.

(ii) If $\mathrm{d}>d_{L o S}+w$, then $\mathrm{L}(\mathrm{d}, \mathrm{p})=L_{N L o S}(d, p)$.

(iii) Otherwise linearly interpolate between the values.

$$
\begin{gathered}
L_{L o S}\left(d_{L o S}, p\right), L_{N L o S}\left(d_{L o S}+w, p\right) \\
L_{L o S}=L_{L o S}\left(d_{L o S}, p\right) \\
L_{N L o S}=L_{N L o S}\left(d_{L o S}+w, p\right) \\
\mathrm{L}(\mathrm{d}, \mathrm{p})=L_{L o S}+\frac{\left(L_{N L o S}-L_{L o S}\right)\left(d-d_{L o S}\right)}{w}
\end{gathered}
$$

The width $w$ is introduced to provide a transition region between the LoS and NLoS regions. This transition region is seen in the data and typically has a width of $w=20 \mathrm{~m}$. The LoS and NLoS location variability corrections are shown in Table 1 .

In Table 1, it can be seen that the spatial variation rate $\left(\mathrm{p}_{\mathrm{S}}\right)$ is inversely proportional to the distance $\left(\mathrm{d}_{\mathrm{LoS}}\right)$ between transmission and reception, and the loss increases. At $\mathrm{p}_{\mathrm{S}}(50 \%)$ the loss of LoS and NLoS location variability corrections is zero.

\section{Measurement and Results Analysis}

4.1. Measurement Method. A random location was selected for measuring the time change rates, and the RSRP, which is one of the various signals transmitted from the base station using the mobile communication LTE network, was

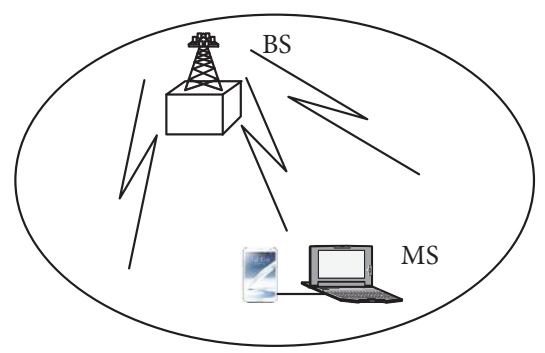

FIGURE 1: Measurement environment.

TABLE 2: Measurements Areas.

\begin{tabular}{lcc}
\hline Indoor & Sangmu restaurant $(\mathrm{A})$ & Lotte World Cup Outlet $(\mathrm{B})$ \\
\hline Outdoor & Gwangcheon terminal square (outdoor) $(\mathrm{C})$ \\
\hline
\end{tabular}

measured using measurement equipment [14, 17, 18]. The measurement was performed at a specific frequency of 879 $\mathrm{MHz}$ using the SKT LTE network in KOREA.

4.1.1. RSRP. Generally, the signal measurement parameters of the physical layer in LTE are divided into four types: RSRP, received signal strength indicator (RSSI), reference signal received quality (RSRQ), and signal-to-interferenceplus-noise ratio (SINR). The RSRP signal, one of the aforementioned parameters, is used as a reference signal [19], and it is measured as follows [14].

4.1.2. Measurement Equipment and Conditions. In Figure 1, a laptop computer loaded with the measurement program (OPTis) and the Galaxy S2 mobile terminal are used for measuring the LTE RSRP signals. Measurement conditions are as follows: SKT LTE base station RSRP signal, 72 calls per hour ( 1 call/50 s), 800 calls ( 1 call/4.5 s), and 72,000 calls (1 call/0.05 s).

4.2. Measurement Area and RSRP Measurement. Changes by busy time and nonbusy time can be compared by chronologically sorting the measured data. Data was measured based on time changes and probability distribution. RSRP signals were measured at certain time intervals during certain time period, and the collected and sorted data were measured. For measurement, indoor and outdoor areas in Gwangju Metro City, Korea, were selected and they are shown in Table 2. The selected areas were a place where a lot of people move in downtown. 
TABLE 3: RSRP measurements in busy time and nonbusy time.

\begin{tabular}{|c|c|c|c|c|c|c|c|}
\hline Area & & $\begin{array}{c}\text { A-1 } \\
\text { busy }\end{array}$ & $\begin{array}{c}\text { A-2 } \\
\text { non-busy }\end{array}$ & $\begin{array}{c}\text { B-1 } \\
\text { busy }\end{array}$ & $\begin{array}{c}\text { B-2 } \\
\text { busy }\end{array}$ & $\begin{array}{c}\text { C-1 } \\
\text { busy }\end{array}$ & $\begin{array}{c}\text { C-2 } \\
\text { Busy }\end{array}$ \\
\hline \multicolumn{2}{|l|}{ Distance $(\mathrm{m})$} & \multicolumn{2}{|c|}{104} & \multicolumn{2}{|c|}{303} & \multicolumn{2}{|c|}{119} \\
\hline \multirow{5}{*}{ Time Rate $\left(\mathrm{p}_{\mathrm{T}} \%\right)$} & 0 & -73.92 & -68.30 & -95.57 & -90.93 & -78.31 & -79.56 \\
\hline & 1 & -73.48 & -68.28 & -91.80 & -90.42 & -58.38 & -77.00 \\
\hline & 50 (Median) & -70.98 & -65.37 & -86.22 & -86.95 & -55.56 & -74.00 \\
\hline & 100 & -64.61 & -63.39 & -79.16 & -82.40 & -53.75 & -60.94 \\
\hline & Average & -70.20 & -65.52 & -85.39 & -86.93 & -55.92 & -73.05 \\
\hline
\end{tabular}

In order to propose a wave propagation model reflecting the characteristics of time/spatial changes, RSRP measured the time rates of the measurement values, at the same place on a certain day and at the same place on another day of the week. Two types of measurements were broadly performed: (1) measurement was conducted for 1 2 hour each during the busy hour and nonbusy hour at the same area (indoor) A; (2) measurement was performed at the same time (busy hour) on different days at the same area (indoor and outdoor) B, C. The results are summarized in Table 3.

4.3. Result Analysis. In Table 3, The RSRP signal in the floating population concentrated areas was affected by the surrounding propagation environment according to the changes in time. The comparison results indicated that the time rates by locations in indoor areas, $1 \%$ and $50 \%$, showed a difference of $2.5 \sim 5.58 \mathrm{dBm}$. On the other hand, in the outdoor area, time rates of $1 \%, 10 \%$, and $50 \%$ showed a difference of approximately $2.82 \sim 3.0 \mathrm{dBm}$.

We confirmed that signal quality is worse than when there is a large floating population in the same indoors (busy time). The measurement at a time rate of $1 \%$ means that the signal quality is bad and the measurement value at $50 \%$ of the time rate indoors and outdoors was similar to the average the total measurement value. Also, we confirmed that signal quality is worse than distance. Therefore, we have confirmed that the time rate was inversely proportional to the busy time with a large floating population and the space rate to the transmission and reception distance.

\section{Proposal of Propagation Model Reflecting the Characteristics of Time/Spatial Changes}

The proposed model parameters that reflect the characteristics of time/spatial changes were shown in Table 4. Also, the reason for the propose model according to the measurement result in Table 3, the measurement environment is the microcell downtown environment in which the multipath fading exists, so that the shadowing parameter exists.

By Table 4 we proposed two models. Proposed model 1 was (5) and the path loss exponent $n$ was selected as 2.7 by considering the measurement environment of downtown. Another proposed model 2 was as in (6).

$$
\begin{aligned}
\mathrm{PL}[\mathrm{dB}]=31.28+10 \mathrm{n} \log \left(\frac{\mathrm{d}}{\mathrm{d}_{0}}\right)+\alpha & \\
\mathrm{n} & =2.7, \mathrm{~d}_{0}=1 \mathrm{~m}, \alpha=-11
\end{aligned}
$$

TABLE 4: The proposed model parameters.

\begin{tabular}{lc}
\hline $\begin{array}{l}\text { Identifying the path } \\
\text { (combined multipath) }\end{array}$ & $\begin{array}{c}\text { Land indoor and outdoor } \\
\text { path }\end{array}$ \\
\hline $\begin{array}{l}\text { Determining the time rates } \\
\text { Determining the required } \\
\text { frequency }\end{array}$ & $1 \%, 50 \%$ \\
\hline $\begin{array}{l}\text { Determining the required } \\
\text { distance }\end{array}$ & $879 \mathrm{MHz}$ \\
\hline $\begin{array}{l}\text { Determining the electric } \\
\text { field strength with regard to } \\
\text { frequency, distance, } \\
\text { transmission antenna } \\
\text { height, and time rate } \\
\text { considering the } \\
\text { transmission antenna } \\
\text { height) }\end{array}$ & $\begin{array}{c}\text { Transmission antenna } \\
\text { height }\end{array}$ \\
& $\begin{array}{c}\text { hb }=5-30 \mathrm{~m} \\
\text { heception antenna height }\end{array}$ \\
& $\begin{array}{c}\text { Transmission and reception } \\
\text { antenna gain } \mathrm{Gb}, \mathrm{Gm}=1 \\
\text { Simulation reflecting the } \\
\text { time rates }\end{array}$ \\
\hline
\end{tabular}

$$
\begin{aligned}
& P L[d B]=42.6+26 \log \left(\frac{d}{d_{0}}\right)+20 \log (f)+\alpha \\
& \mathrm{f}=879 \mathrm{MHz}, \mathrm{d}_{0}=1 \mathrm{~km}, \alpha=-1
\end{aligned}
$$

In Table 5 and Figure 2, FSL, COST 231, proposed model 1, and proposed model 2 were compared with measured values at $1 \%$ and $50 \%$ of the time rates. The (A), (B), and (C) in Table 5 are indoor and outdoor area in Table 2 . The proposed models 1 and 2 were compared with measurement values of the time rate $50 \%$ at measurement places. The difference was $0.76 \sim 1.05 \mathrm{dBm}$ at $400 \mathrm{~m}$ below indoor, the proposed models were approximately the time rate of $50 \%$. At the indoor $200 \mathrm{~m}$ below and the outdoor $200 \mathrm{~m}$ below, the difference between time rate $50 \%$ and the proposed models was $3.76 \sim 3.94$ and $2.32 \sim 2.44 \mathrm{dBm}$, respectively. As a result, we have confirmed that proposed model 1 can be more accurately predicted at outdoor. On the other hand, proposed model 2 can be more accurately predicted by comparing the measured values at indoor below 400. Below 200 indoor, proposed model 1 was similar to proposed model 2.

\section{Conclusions}

Rapidly rising demand for radio communication and the explosion in the number of mobile communications service subscribers have led to the need for optimization in the 
TABLE 5: Compare with the proposed model and the measurement results.

\begin{tabular}{|c|c|c|c|c|c|c|c|c|}
\hline \multirow{2}{*}{$\begin{array}{l}\text { Distance } \\
(\mathrm{m})\end{array}$} & \multirow{2}{*}{\multicolumn{2}{|c|}{ Measurement Area }} & \multicolumn{2}{|c|}{ Measurement $[\mathrm{dB}]$} & \multirow{2}{*}{$\begin{array}{l}\text { Free Space } \\
\text { Loss model }\end{array}$} & \multirow{2}{*}{$\begin{array}{c}\text { COST } 231 \\
\text { model }\end{array}$} & \multirow{2}{*}{$\begin{array}{c}\text { Proposed } \\
\text { model } 1\end{array}$} & \multirow{2}{*}{$\begin{array}{c}\text { Proposed } \\
\text { model } 2\end{array}$} \\
\hline & & & Time Rate & Time Rate & & & & \\
\hline $\begin{array}{l}200 \\
\text { below }\end{array}$ & \multirow{2}{*}{ Indoor } & (A) & 73.48 & 70.98 & 71.28 & 75.48 & 74.74 & 74.92 \\
\hline $\begin{array}{l}400 \\
\text { below }\end{array}$ & & (B) & 91.80 & 86.22 & 80.91 & 88.00 & 87.27 & 86.98 \\
\hline $\begin{array}{l}200 \\
\text { below }\end{array}$ & Outdoor & (C) & 77.00 & 74.00 & 72.79 & 77.44 & 76.32 & 76.44 \\
\hline
\end{tabular}

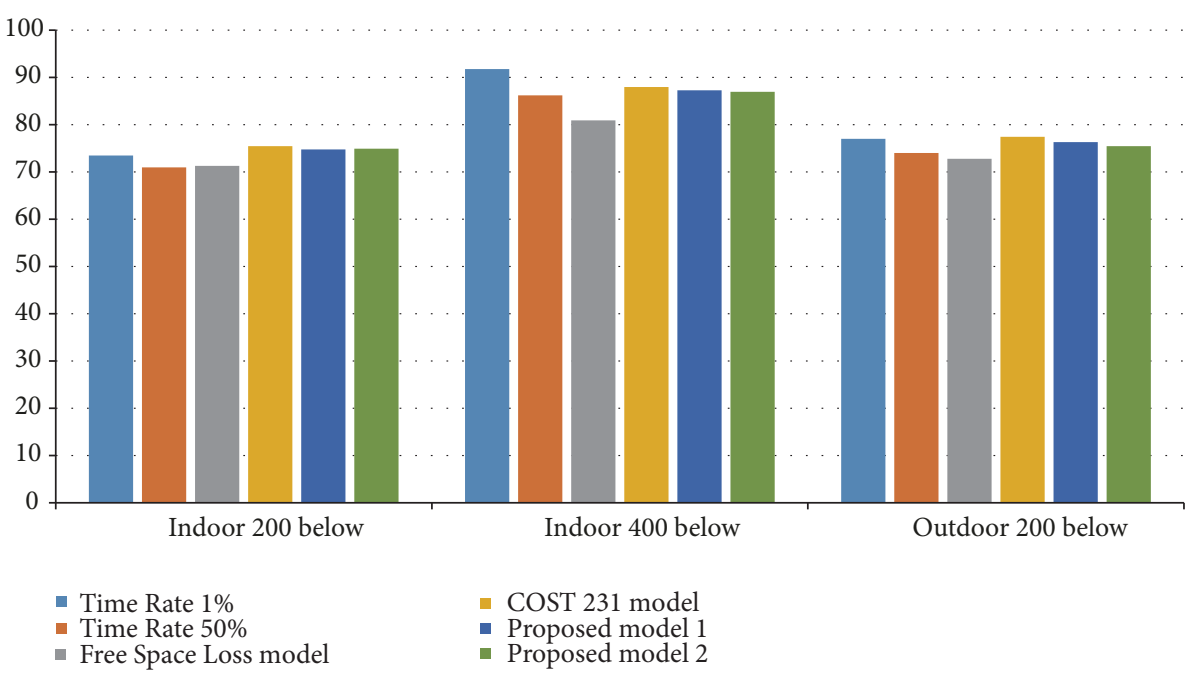

FIGURE 2: Comparison of time rates ( $1 \%$ and $50 \%)$ and proposed models.

development of fifth-generation (5G) mobile communication systems.

In this paper, we investigated the concept of space and time rates of change through radio wave measurements. The concept of space change was applied to LoS and NLoS, indoor and outdoor, and busy time and nonbusy time were applied as the concept of time change. The spatial variation rate (p) is inversely proportional to the distance between transmission and reception, and the loss increases. RSRP measurements of LTE signals were made in consideration of the time change rate of $1 \%$ and $50 \%$ in three locations (indoor 2, outdoor 1 in downtown). We confirmed that signal quality is worse than when there is a large floating population in the same indoors (busy time). The measurement at a time rate of $1 \%$ means that the signal quality is bad and the measurement value at $50 \%$ of the time rate indoors and outdoors was similar to the average the total measurement value. Also, we confirmed that signal quality is worse than distance. Therefore, we have confirmed that the time rate was inversely proportional to the busy time with a large floating population and the space rate to the transmission and reception distance. Based on these results, we proposed two propagation models in microcell downtown environment. The forecast results using proposed models 1 and 2 were better than the COST231 model in both indoor and outdoor measured places. It was predicted between a time rate of $1 \%$ and $50 \%$ indoor within $400 \mathrm{~m}$ and outdoor within $200 \mathrm{~m}$.

In the future, we will study the propagation model of $5 \mathrm{G}$ mobile communications as well as the current $4 \mathrm{G}$ communications using artificial intelligence technology.

\section{Data Availability}

Previously reported data were used to support this study and these prior studies are cited at relevant places within the text as [14]. The data used to support the findings of this study are included in the article.

\section{Conflicts of Interest}

The authors declare that there are no conflicts of interest regarding the publication of this paper.

\section{Acknowledgments}

This study was supported by research fund from Chosun University, 2018. 


\section{References}

[1] T. S. Rappaport, Y. Xing, G. R. MacCartney, A. F. Molisch, E. Mellios, and J. Zhang, "Overview of millimeter wave communications for fifth-generation (5G) wireless networks-with a focus on propagation models," IEEE Transactions on Antennas and Propagation, vol. 65, no. 12, pp. 6213-6230, 2017.

[2] A. Osseiran, F. Boccardi, V. Braun, K. Kusume, P. Marsch, M. Maternia et al., "Scenarios for 5G mobile and wireless communications: the vision of the METIS project," IEEE Communications Magazine, vol. 52, no. 5, pp. 26-35, 2014.

[3] M. Landmann, K. Sivasondhivat, J.-I. Takada, I. Ida, and R. Thomä, "Polarization behavior of discrete multipath and diffuse scattering in urban environments at $4.5 \mathrm{GHz}$," Eurasip Journal on Wireless Communications and Networking, vol. 2007, Article ID 57980, 2007.

[4] V. Degli-Esposti, D. Guiducci, A. de'Marsi, P. Azzi, and F. Fuschini, "An advanced field prediction model including diffuse scattering," IEEE Transactions on Antennas and Propagation, vol. 52, no. 7, pp. 1717-1728, 2004.

[5] J. Poutanen, J. Salmi, K. Haneda, V.-M. Kolmonen, F. Tufvesson, and P. Vainikainen, "Propagation characteristics of dense multipath components," IEEE Antennas and Wireless Propagation Letters, vol. 9, pp. 791-794, 2010.

[6] J. Järveläinen and K. Haneda, "Sixty gigahertz indoor radio wave propagation prediction method based on full scattering model," Radio Science, vol. 49, no. 4, pp. 293-305, 2014.

[7] B.-J. Lee, J.-P. Cho, I.-H. Ra, and K.-S. Kim, "Propagation characterization based on geographic location variation for $5 \mathrm{G}$ small cells," Mobile Information Systems, vol. 2017, Article ID 7028431, 8 pages, 2017.

[8] K. Kitao and S. Ichitsubo, "Path loss prediction formula for urban and suburban areas for $4 \mathrm{G}$ systems," in IEEE, IEEE, Melbourne, Vic., Australia, 2006.

[9] S. Hiroshi, Y. Kenya, I. Takashi, and N. Yuichi, "Estimation of high frequency NLOS path loss in street-cell environment," in IEEE, pp. 336-340, IEEE, Hoi an, Vietnam, 2008.

[10] S. M. S. Majedi and F. Farzaneh, "A new empirical-physical method for calculation of path loss for fixed wireless access in suburban areas," in Proceedings of the 2008 International Symposium on Telecommunications, 2008.

[11] K. T. Herring, J. W. Holloway, D. H. Staelin, and D. W. Bliss, "Path-Loss characteristics of urban wireless channels," IEEE Transactions on Antennas and Propagation, vol. 58, no. 1, 2010.

[12] S. Y. Seidel and T. S. Rappaport, " $914 \mathrm{MHz}$ path loss prediction models for indoor wireless communications in multifloored buildings," IEEE Transactions on Antennas and Propagation, vol. 58 , no. $1,2010$.

[13] H. El-Sallabi, D. S. Baum, P. Zetterberg, P. Kyösti, T. Rautiainen, and C. Schneider, "Wideband spatial channel model for MIMO systems at $5 \mathrm{GHz}$ in indoor and outdoor environments," in IEEE, 2006.

[14] S.-K. Noh, G.-S. Kim, S. W. Kim, and D. Choi, "Measurements and analysis for proposal of propagation models considering time and spatial variation of propagation environments in the micro-wave band," in Proceedings of the 5th International Conference on Information and Communication Technology Convergence, ICTC 2014, pp. 456-461, Republic of Korea, October 2014.

[15] ITU-R P.1411-5, http://www.itu.int/pub/R-REC/en.

[16] ITU-R P.370, P.311, P.1410, P.1411, P.1470, http://www.itu.int/pub/ R-REC/en.
[17] M. NarandDit, C. Schneider, and W. Kotterman, "Quantification of scenario distance within generic winner channel model," International Journal of Antennas and Propagation, vol. 2013, Article ID 176704, 17 pages, 2013.

[18] M. S. Hossain, R. Adhikary, and N. Yesmin, "Performance evaluation of WINNER-II channel model for long term evolution (LTE)," International Journal of Scientific \& Engineering Research, vol. 4, no. 5, 2013.

[19] https://www.3gpp.org/, 36.214. 


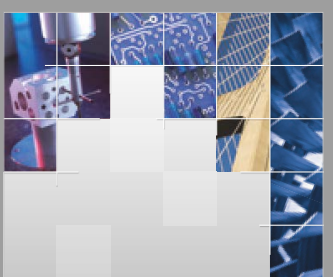

\section{Enfincering}
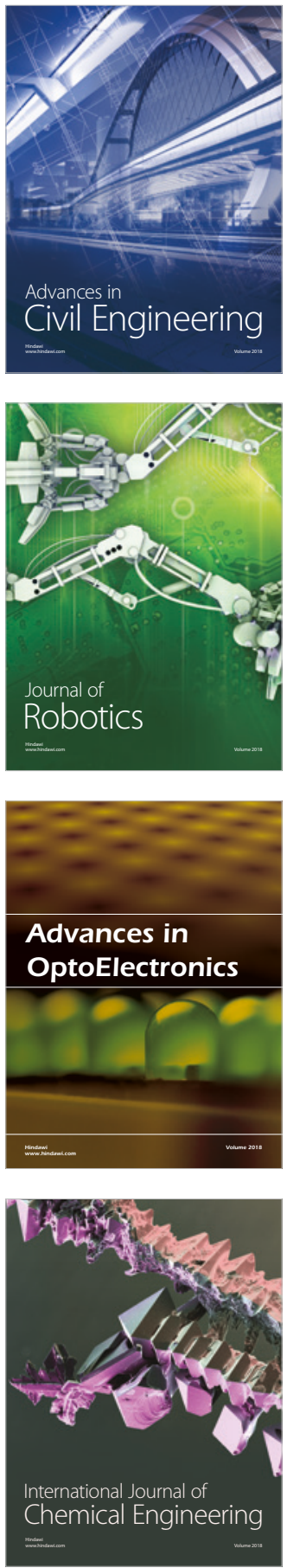

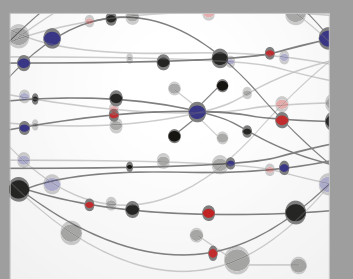

\section{Rotating \\ Machinery}

The Scientific World Journal

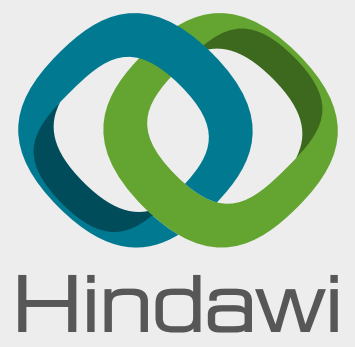

Submit your manuscripts at

www.hindawi.com
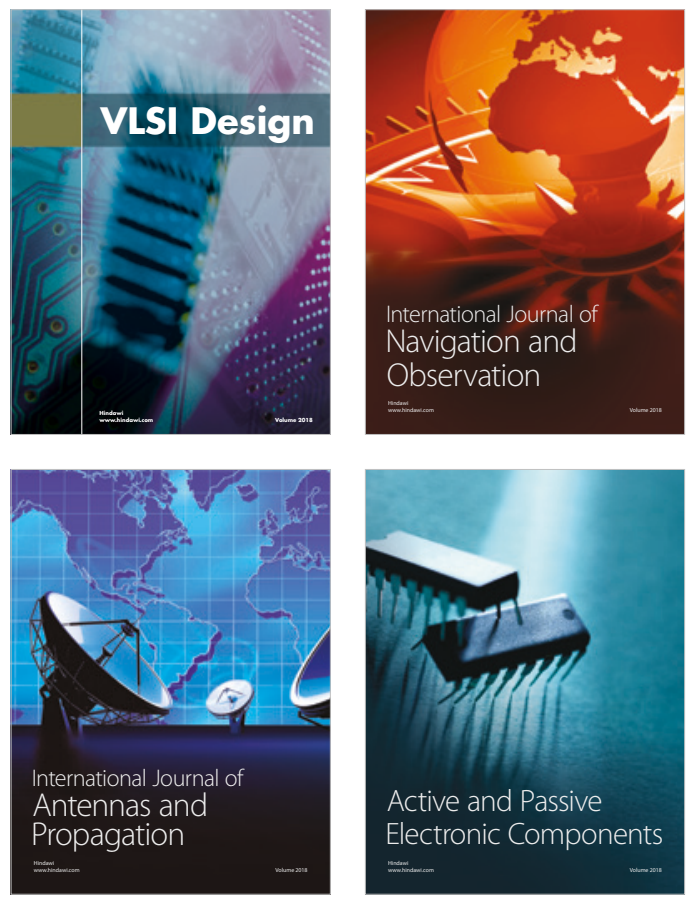
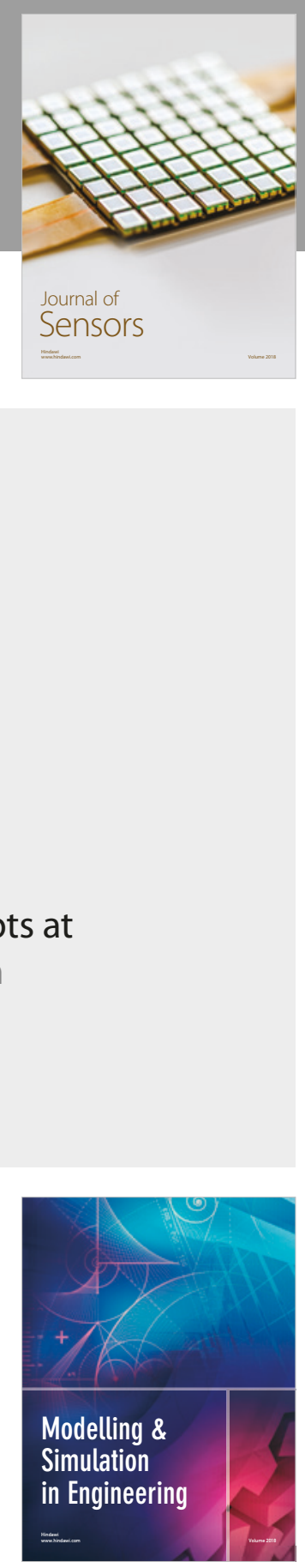

\section{Advances \\ Multimedia}
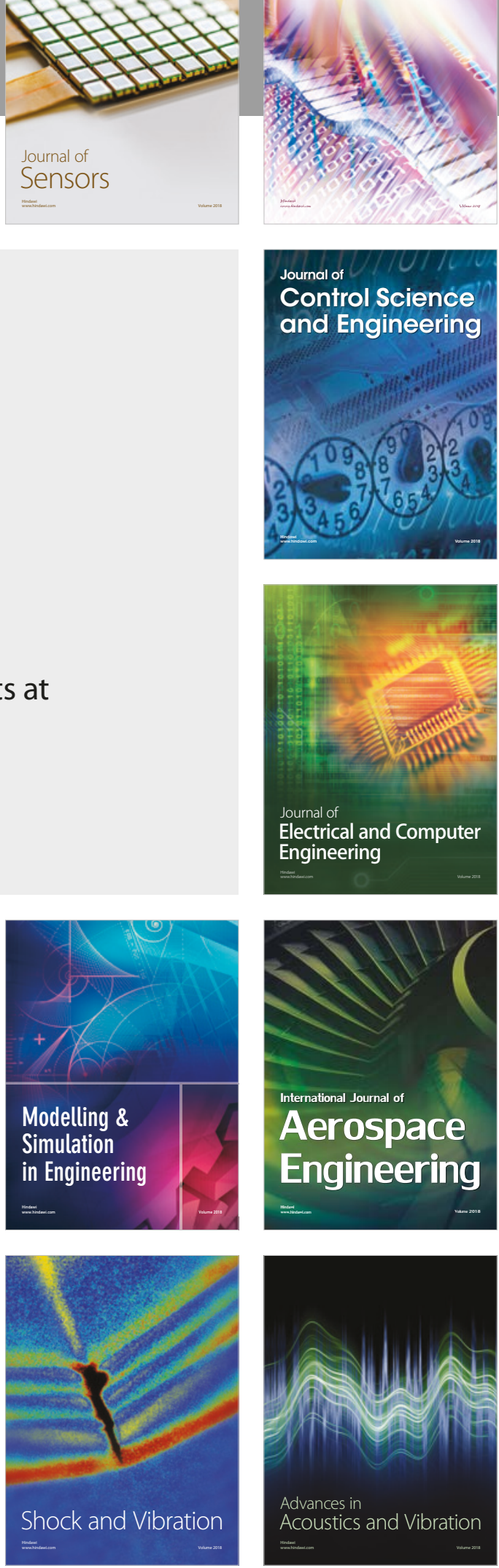